\title{
AVALIAÇÃO DA QUALIDADE DE AMOSTRAS COMERCIAIS DE DOCE DE LEITE PASTOSO - COMPOSIÇÃO QUÍMICA ${ }^{1}$
}

\author{
Ivo Mottin DEMIATE ${ }^{2}{ }^{*}$, Francisco Eneias KONKEL ${ }^{3}$, \\ Ricardo Alexandre PEDROSO ${ }^{3}$
}

\begin{abstract}
RESUMO
O doce de leite é um alimento regional, produzido principalmente na Argentina e no Brasil, apresentando alguns problemas com relação a qualidade. O presente trabalho teve por objetivo avaliar a composição química de amostras comerciais de doce de leite pastoso $(n=42)$, para verificar se poderia estar havendo alguma fraude. Além dos componentes lácteos (lactose, proteína, lipídios e cinzas), determinou-se também o conteúdo de amido das amostras O teor de amido foi determinado enzimaticamente e os resultados revelaram elevados teores desse polissacarídeo. Em 15 amostras foram encontrados teores superiores a 3,0\% de amido, com valor máximo de 7,8\%. Umidades acima da permitida pela legislação [2] foram detectadas em dez amostras, com valor máximo de 37,2\%. A análise estatística dos resultados da composição química das amostras revelou correlação positiva entre os teores de componentes do leite (lactose, proteína, lipídios e cinzas), que se correlacionaram negativamente com os conteúdos de amido revelando que, em alguns casos, o amido é adicionado para reduzir os custos de produção o que se constitui em uma fraude. A análise de componentes principais evidenciou a diferenciação das amostras de acordo com os conteúdos de amido e componentes do leite e também pelos teores de sacarose.
\end{abstract}

Palavras-chave: doce de leite; amido; qualidade.

\section{SUMMARY}

QUALITY EVALUATION OF COMMERCIAL SAMPLES OF DOCE DE LEITE-CHEMICAL COMPOSITION. Doce de leite is a regional food produced mainly in Argentina and Brazil, presenting some problems related with quality. The present paper aims to determine the chemical composition of commercial samples (n $=42$ ) in order to search for some irregularities. The compounds present in milk (lactose, protein, lipids and ash) were determined as well as starch. The starch content was enzymatically determined and the results showed high levels of polyssacharide. On 15 samples levels higher than $3.0 \%$ of starch were found, with $7.8 \%$ as a maximum. Moisture levels higher than that allowed by Brazilian legislation [2] were detected on ten samples, with a maximum of $37.2 \%$. The statistical analysis of the chemical composition showed that there was a positive correlation between milk compounds (lactose, protein, lipids and ash) present in the samples and that these compounds were negatively correlated with starch, showing that in some cases starch is added for reducing costs, which can be characterized as a fraud. The principal component analysis evidenced sample differentiation due to their milk compounds, starch and sucrose contents.

Keywords: doce de leite; starch; quality.

${ }^{1}$ Recebido para publicação em 03/01/01. Aceito para publicação em 26/04/01.

${ }^{2}$ Professor Adjunto do SCAT/DEZOO, Universidade Estadual de Ponta Grossa (UEPG) - Praça Santos Andrade, s/n, CEP 84010330 Ponta Grossa PR e-mail:demiate@interponta.com.br

${ }^{3}$ Acadêmicos do Curso de Engenharia de Alimentos da UEPG, bolsistas de iniciação científica do programa PIBIC - UEPG/CNPq *A quem a correspondência deve ser enviada.

\section{1 - INTRODUÇÃO}

$O$ doce de leite, também encontrado em referências internacionais como dulce de leche, é um importante alimento produzido e comercializado principalmente na Argentina e no Brasil $[16,21,17,11]$. Trata-se de um produto obtido pelo cozimento de leite adicionado de sacarose, que adquire coloração, consistência e sabor característicos em função de reações de escurecimento não enzimático [7, 9], sendo muito apreciado pelos consumidores. É amplamente empregado como ingrediente para a elaboração de alimentos como confeitos, bolos, biscoitos, sorvetes e também consumido diretamente na alimentação como sobremesa ou acompanhado de pão, torradas ou de queijo. Segundo PAULETTI et al [14], seu consumo está em expansão na Europa e nos Estados Unidos.

A produção de doce de leite no Brasil é feita por muitas empresas, desde as caseiras até as grandes, com distribuição em todo o país. A produção regionalizada, principalmente na América do Sul [16], explica a existência de poucas referências na literatura científica a respeito desse produto. A maioria dos trabalhos disponíveis foram desenvolvidos na Argentina ou no Brasil e estão relacionados ao processamento e à caracterização da qualidade. Há, entretanto, falta de dados sobre a composição química de amostras, especialmente em relação a possibilidade da ocorrência de fraudes. O doce de leite não apresenta uniformidade, apesar de ser produzido em grande volume e amplamente empregado como um ingrediente alimentício, o que pode ser comparado com o que ocorre com o polvilho azedo, outro produto regional $[5,6,4]$.

$\mathrm{Na}$ Argentina, no início dos anos 90 eram produzidas cerca de 60.000 ton./ano, das quais aproximadamente $50 \%$ eram destinadas à indústria de confeitaria. A aplicação industrial gerou novas exigências com relação a qualidade, principalmente em termos de cor e textura e a necessidade de metodologias capazes de eliminar a falta de normalização do produto [14].

O doce de leite foi listado como um dos produtos que se apresenta com parâmetros contraditórios na legislação brasileira [20]. De acordo com a legislação [2], o doce de leite pastoso deve conter teores máximos de umidade de 30 e de cinzas de 2,0\% (p/p). O teor mínimo de proteínas deve ser de $5,0 \%$ (p/p) e o conteúdo de matéria graxa deve estar entre 6,0 e 9,0\% (p/p). Ainda conforme a legislação, a sacarose é empregada na obtenção do produto e a quantidade máxima admitida na fabricação é de $30 \mathrm{~kg} / 100 \mathrm{~L}$ de leite. Amidos ou ami- 
dos modificados são admitidos em proporção não superior a $0,5 \mathrm{~g} / 100 \mathrm{~mL}$ de leite, assim como mono ou dissacarídeos que substituam a sacarose em no máximo $40 \%$ (p/p). Creme e sólidos de origem láctea também são tolerados como ingredientes opcionais. A lista de aditivos é grande, havendo limites máximos para a maioria deles. A enzima b-galactosidase e o sal bicarbonato de sódio são considerados como coadjuvantes.

O doce de leite pastoso apresenta teor de sólidos de cerca de $70 \%$, com coloração caramelo de intensidade variável [1], desde creme claro até marrom muito escuro, em função da intensidade das reações de Maillaro e da caramelização [7].

O doce de leite é basicamente leite concentrado adicionado de açúcar. Apresenta elevado valor nutricional por conter proteínas e minerais, além do conteúdo energético. É um alimento menos perecível que o leite e de grande aceitação sensorial [11]. O Quadro 1 mostra uma comparação entre a constituição do leite de vaca integral e do doce de leite pastoso.

QUADRO 1. Comparação entre a constituição do leite de vaca integral e do doce de leite pastoso.

$\begin{array}{lcc}\text { Constituinte }(\mathrm{g} \%) & \text { Leite de vaca integral } & \text { Doce de leite pastoso } \\ \text { Água } & 87,6 & 26,6 \\ \text { Proteínas } & 3,3 & 8,3 \\ \text { Lipídios } & 3,4 & 8,3 \\ \text { Lactose } & 4,7 & 10,2 \\ \text { Outros açúcares } & 0,0 & 45,3 \\ \text { Cinzas } & 0,7 & 1,4\end{array}$

Fonte: extraído de MARTINS \& LOPES [11].

Além da sacarose, costuma-se adicionar cerca de $2,0 \%$ de glucose, em relação ao peso do leite, que contribui para a textura e brilho do produto. O conteúdo de lipídios é importante para o rendimento e textura [11].

A baixa umidade do doce de leite pastoso melhora a conservação do produto, porém facilita o aparecimento de arenosidade [19], um defeito percebido sensorialmente. A porcentagem de açúcar adicionado varia de 18 a $28 \%$ sobre o peso de leite [19]. Esses autores consideram uma formulação com 100 partes de leite, 18 a 20 partes de sacarose, duas partes de glucose (em peso), podendo o teor de açúcares adicionados atingir 25 a $28 \%$, para a produção de doce de leite pastoso.

O tempo de cocção está relacionado com a coloração e umidade desejadas, ao tipo de equipamento utilizado, ao teor de sólidos totais inicial e ao fluxograma adotado no processamento [11].

As embalagens de doce de leite devem proteger contra a perda de umidade e dificultar a passagem de oxigênio, além de impedir a contaminação microbiológica [11]. As embalagens rígidas mais comuns são os copos e potes de vidro e as latas, que apresentam como vantagem o fechamento hermético. As embalagens semirígidas, termoformadas, principalmente de polipropileno, apresentam como vantagens o baixo peso, a resistência e razoável proteção ao oxigênio e à perda de umidade [11].
PAVLOVIC et al[15] estudaram a reação de Maillard que ocorre durante a produção de doce de leite, responsável pela coloração e flavorcaracterísticos do produto. Essa reação altera também o valor nutricional. Para esse estudo, os autores produziram doce de leite a partir de leite de vaca pasteurizado padronizado $(3,0 \% \mathrm{p} / \mathrm{p}$ de gordura), com a acidez corrigida para $13^{\circ} \mathrm{D}$ e $\mathrm{pH}$ para 6,75 com a adição de bicarbonato de sódio. Açúcar refinado comercial (sacarose) na proporção de $20 \%$ $(\mathrm{p} / \mathrm{v})$, foi misturado ao leite e a mistura aquecida a $90^{\circ} \mathrm{C}$ em tacho de paredes duplas (capacidade para $300 \mathrm{~L}$ ) por 150 min. sob agitação. Amostras foram coletadas do tacho após terem atingido a concentração de $70^{\circ}$ Brix e pH 6,10 a intervalos de 30 minutos. Os autores acompanharam a formação de 5-hidróxi-metil-furfural (5-HMF) e a absorbância a $420 \mathrm{~nm}$, relacionada a pigmentos ligados às proteínas. A análise de aminoácidos indicou redução de $33 \%$ no conteúdo de lisina, $11 \%$ no de arginina e $10 \%$ no de histidina. Concluíram, finalmente, que o processamento do doce de leite diminuiu o valor nutricional do leite devido a perda de aminoácidos, especialmente lisina. Isso foi correlacionado com a formação de 5-HMF mas não com o desenvolvimento de cor, que ocorreu principalmente nos últimos $30 \mathrm{~min}$. do processamento (entre 120 e 150min.), quando os níveis de lisina e de 5-HMF não variaram.

NAVARRO et al [12] estudaram propriedades reológicas de doces de leite argentinos e detectaram diferenças entre os produtos em função da presença e dos tipos de agentes espessantes.

ROVEDO et al [18] avaliaram o efeito do $\mathrm{pH}$ e da temperatura no comportamento reológico de amostras de doce de leite comercial argentino. Os autores destacaram a existência de dois tipos de doces de leite na Argentina: o doce de leite para uso doméstico e àquele de uso em confeitaria. O primeiro é consumido como sobremesa e o segundo é preferencialmente usado em confeitaria devido a sua maior viscosidade, que resulta, de acordo com os autores, da adição de amido em sua formulação. A composição das amostras analisadas por ROVEDO et al [18] era, para aquela de uso doméstico, leite $(80 \%)$, sacarose $(16 \%)$ e xarope de glucose $(4,0 \%)$; o doce de leite para confeitaria foi produzido a partir da mesma formulação, adicionado de 2,0\% de amido, como espessante. Em ambos os tipos de produtos, o conteúdo total de sólidos foi de $71 \%$. Os autores concluíram que a viscosidade aparente do doce de leite de uso doméstico foi alterada pelo $\mathrm{pH}(3,0,4,7$, $8,3$ e 9,4$)$ e temperatura $\left(25,40\right.$ e $\left.55^{\circ} \mathrm{C}\right)$ das amostras. A acidificação diminuiu e a alcalinização aumentou a viscosidade aparente. Em ambos os casos a viscosidade aparente aumentou durante a armazenagem. Em função do amido adicionado (2,0\%), o doce de leite para confeitaria apresentou maior consistência e comportamento mais pseudoplástico que aquele de uso doméstico.

O presente trabalho foi desenvolvido com o objetivo de detectar eventuais fraudes, assim como falhas na rotulagem nutricional e nas informações relativas aos ingredientes previstos na legislação, que estabele- 
cem alguns limites mínimos (proteína, por exemplo) e máximos (umidade, cinzas e amido).

\section{2 - MATERIAL E MÉTODOS}

\section{1 - Material}

Amostras de doce de leite pastoso foram adquiridas em estabelecimentos comerciais do Paraná e de São Paulo e empregadas nas análises. Das 42 amostras analisadas, 5 foram produzidas no Rio Grande do Sul, 6 em Santa Catarina, 12 no Paraná, 11 em São Paulo, 7 em Minas Gerais e 1 em Goiás.

Amostras de doce de leite adicionadas de quantidades conhecidas de amido foram produzidas no laboratório e analisadas para se aferir a metodologia, que se mostrou adequada aos objetivos do trabalho.

Os rótulos das embalagens foram transcritos e os dados comparados com os resultados experimentais obtidos. Ingredientes e aditivos presentes na descrição dos rótulos foram considerados, assim como as informações nutricionais e o período de validade dos produtos, quando disponíveis.

\section{2 - Métodos}

\subsection{1 - Composição química das amostras}

\section{- Umidade}

A umidade das amostras foi determinada gravimetricamente após secagem em estufa a $105^{\circ} \mathrm{C}$ por 4 horas [10].

\section{- Açúcares totais e redutores}

Os açúcares totais foram determinados colorimetricamente [8], após hidrólise da sacarose com extrato enzimático (invertase) obtido de Saccharomyces cerevisiae [23] e os açúcares redutores, conforme SOMOGYI [22] e NELSON [13]. Como açúcares redutores foram detectados lactose e glucose simultaneamente.

\section{- Glucose}

O teor de glucose foi determinado por método enzimático, de acordo com DAHLQUIST [3] e descontado do teor de açúcares redutores. Para se calcular a lactose foi construída uma reta-padrão para corrigir os valores, pois o poder redutor de dissacarídeos redutores é menor que o de monossacarídeos.

\section{- Proteínas, lipídios e cinzas}

As proteínas foram quantificadas pelo método de micro-Kjeldahl [10]. O conteúdo de lipídios foi determinado pelo emprego de lactobutirômetro de Gerber [10]. O teor de cinzas foi medido gravimetricamente após calcinação das amostras em mufla a $550^{\circ} \mathrm{C}$ por 4 horas [10].

\section{- Amido}

As amostras livres de açúcares solúveis foram então colocadas em tubos de ensaio com tampa para a hidrólise do amido. Adicionaram-se $10 \mathrm{~mL}$ da enzima
Termamyl $120 \mathrm{~L}^{\circledR}$ e cálcio (40ppm) e os tubos foram colocados em um banho de água em ebulição, no qual foram mantidos por 15 minutos. Foram resfriados e o pH ajustado para 4,5 com ácido acético. Para completar a hidrólise foram adicionados $20 \mathrm{~mL}$ da enzima AMG $300 \mathrm{~L}^{\circledR} \mathrm{e}$ os tubos levados a um banho de água mantido a $60^{\circ} \mathrm{C}$ por 24 horas. O volume final das amostras hidrolisadas não ultrapassava $10 \mathrm{~mL}$.

As amostras foram retiradas quantitativamente dos tubos nos quais ocorreu a hidrólise e completou-se o peso para $10 \mathrm{~g}$ com água deionizada. Transferiu-se quantitativamente esses $10 \mathrm{~g}$ para sacos de diálise que foram colocados em frascos erlenmeyer contendo $90 \mathrm{~g}$ de água deionizada. Procedeu-se a diálise por 24 horas a $45^{\circ} \mathrm{C}$ e o teor de glucose liberado foi determinado enzimaticamente [3] e corrigido para amido $\left(x_{0}, 9\right)$.

\subsection{2- Análise dos dados}

Os resultados foram analisados pelo emprego do software STATISTICA versão 5.0 (StatSoft, Tulsa OK, EUA) para obtenção de histogramas, estatística descritiva e de matriz de correlação. A análise multivariada qualitativa (análise de componentes principais) também foi empregada na exploração dos dados, com o emprego do software EINSIGHT 3.0 (Infometrix, Seattle WA, EUA).

\section{3 - RESULTADOS E DISCUSSÃO}

As amostras de doce de leite pastoso foram caracterizadas em relação a suas composições químicas e os resultados são mostrados nos Quadros 1 e 2 e nas Figuras 1 a 9.

\section{1 - Umidade das amostras}

As amostras apresentaram-se heterogêneas em relação aos conteúdos de umidade, sendo que os valores oscilaram desde 19,0 até 37,2\%. A legislação limita a $30,0 \%$ o valor máximo permitido, no entanto foram encontradas 10 amostras com umidades acima desse valor. A Figura 1 mostra o histograma de distribuição das amostras de doce de leite em relação aos conteúdos de umidade. A maioria das amostras $(n=32)$ apresentou teores entre 22 e $32 \%$ de umidade.

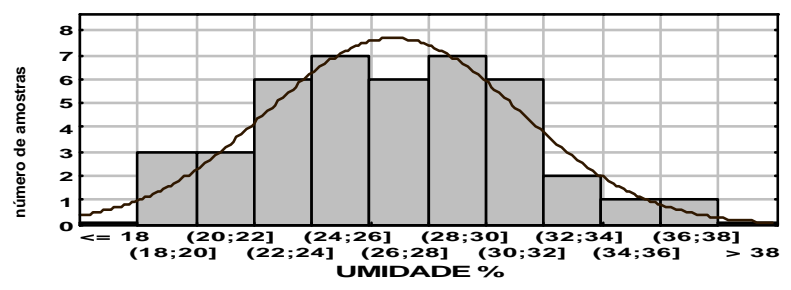

FIGURA 1. Histograma de distribuição de amostras de doce de leite $(n=42)$ em relação aosconteúdos de umidade.

\section{2 - Teor de açúcares nas amostras}

\section{- Lactose}

Os teores de lactose das amostras são mostrados na Figura 2. A lactose é o açúcar de origem animal 
mais importante na alimentação humana, sendo um dissacarídeo abundante no leite, encontrado em concentrações próximas a 5,0\% e responsável pelo gosto doce do produto. Entre as particularidades físico-químicas, apresenta baixa solubilidade quando comparada a outros açúcares comuns na alimentação e pode causar arenosidade no doce de leite [19].

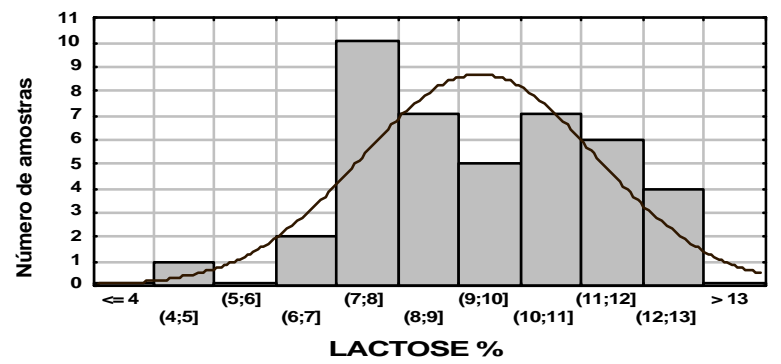

FIGURA 2. Histograma de distribuição de amostras de doce de leite $(n=42)$ em relação aosconteúdos de lactose.

Os teores de lactose encontrados nas amostras variaram desde 4,7 até $12,7 \%$. Em apenas uma amostra há indicação no rótulo do emprego de lactase, porém o baixo conteúdo de lactose é difícil de ser explicado em alguns casos. Mas, como será mostrado adiante, outros componentes (proteínas, cinzas, lipídios) que indicam a presença de leite no produto foram encontrados em baixas concentrações em certas amostras, o que pode estar associado a altos teores de amido, empregado para baixar custos de produção.

\section{- Sacarose}

A sacarose é o principal açúcar adicionado ao leite para a produção do doce de leite. No produto final constitui o principal componente da matéria seca. A Figura 3 mostra os teores de sacarose nas amostras.

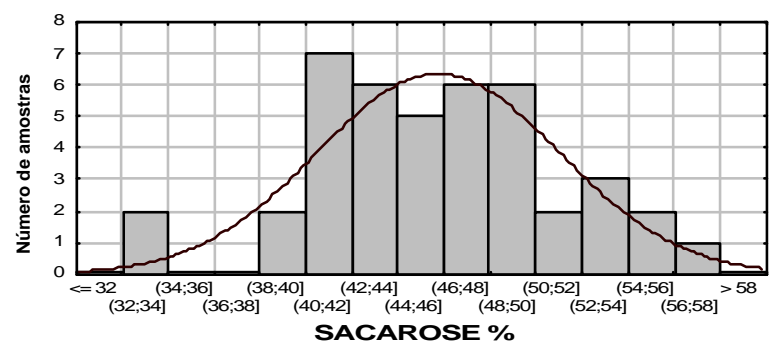

FIGURA 3. Histograma de distribuição de amostras de doce de leite $(n=42)$ em relação aosconteúdos de sacarose.

Os resultados revelam que os teores de sacarose das amostras oscilaram entre 32,7 a 56,6\%. Duas amostras apresentaram valores baixos de sacarose e conseqüentemente elevados de umidade. $\mathrm{Na}$ maioria das amostras $(n=30)$ o conteúdo de sacarose variou de 40 a $50 \%$.

\section{- Glucose}

A glucose pode ser adicionada à formulação do doce de leite para melhorar a aparência do produto, principalmente o brilho. Os teores de glucose encontrados são mostrados na Figura 4.

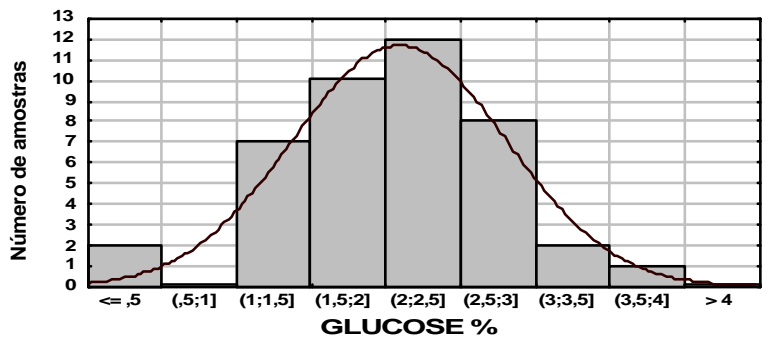

FIGURA 4. Histograma de distribuição de amostras de doce de leite $(n=42)$ em relação aosconteúdos de glucose.

A presença de glucose foi detectada em todas as amostras analisadas, em quantidades que variaram de 0,4 a 3,9\%. A maioria das amostras tinha entre 1,0 e $3,0 \%$ de glucose (37 amostras). É interessante destacar que em apenas 26 amostras constava nos rótulos a adição de glucose.

\section{3 - Conteúdo de proteína das amostras}

O doce de leite, segundo a Portaria n. 0 354, de 04 de setembro de 1997 [2], deve apresentar teores mínimos de proteína de 5,0\%. Os valores encontrados e a distribuição das amostras estão ilustrados na Figura 5 . Considerando-se a elaboração do doce de leite, a partir de leite e de sacarose, é difícil explicar conteúdos de proteína desproporcionais aos teores médios do leite $(3,2 \%)$. Entretanto, a adição de soro de leite pode contribuir para alguma diferença nessa proporcionalidade, assim como a adição de amido.

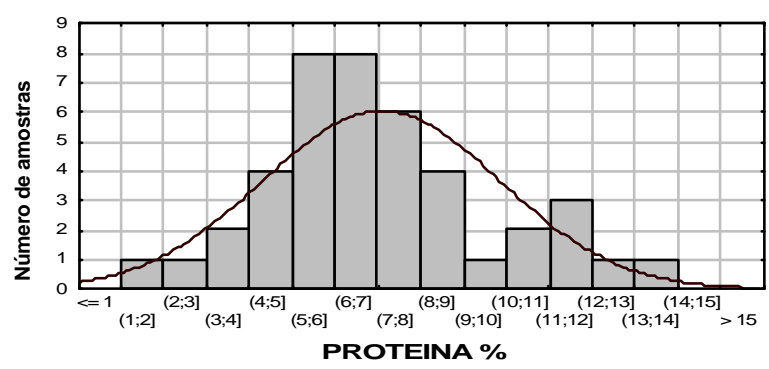

FIGURA 5. Histograma de distribuição de amostras de doce de leite $(n=42)$ em relação aosconteúdos de proteína.

A Figura 5 revela que oito amostras apresentaram teores de proteína abaixo do valor mínimo exigido pela legislação. Os valores oscilaram desde 1,4 até 13,9\% nas 42 amostras analisadas.

\section{4 - Conteúdo de lipídios das amostras}

O teor de lipídios das amostras analisadas variou desde a ausência, em uma amostra de doce de leite desnatado, até 8,4\%. A Figura 6 mostra esses valores para todas as amostras estudadas.

O conteúdo de lipídios esperado para doces obtidos de leite de vaca integral deveria ser de cerca de $8,0 \%$ [11], no entanto, a maioria das amostras apresentou valores mais baixos. Devido ao grande interesse tecnológico pela gordura de leite na indústria láctea e observando-se os resultados na Figura 6, pode-se 
sugerir o uso de leite com baixos teores de gordura na elaboração da maior parte das amostras analisadas.

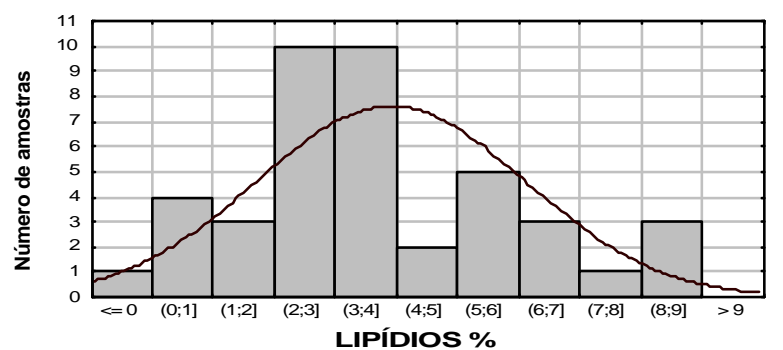

FIGURA 6. Histograma de distribuição de amostras de doce de leite $(n=42)$ em relação aos conteúdos de lipídios.

\section{5 - Conteúdo de cinzas das amostras}

O conteúdo de cinzas foi determinado em 28 das 42 amostras e os resultados são mostrados graficamente na Figura 7. O teor de cinzas é um dos melhores indicadores da presença de leite no produto, pois é um valor constante nessa matéria-prima. Há uma limitação na legislação que admite o valor máximo de 2,0\% de cinzas no doce de leite. Como é permitida a adição de bicarbonato de sódio, e, também de alguns outros sais na produção do doce de leite, pode haver valores elevados de cinzas. Baixos valores, por outro lado, podem indicar que os produtos foram obtidos com pouco leite ou outras matérias-primas lácteas.

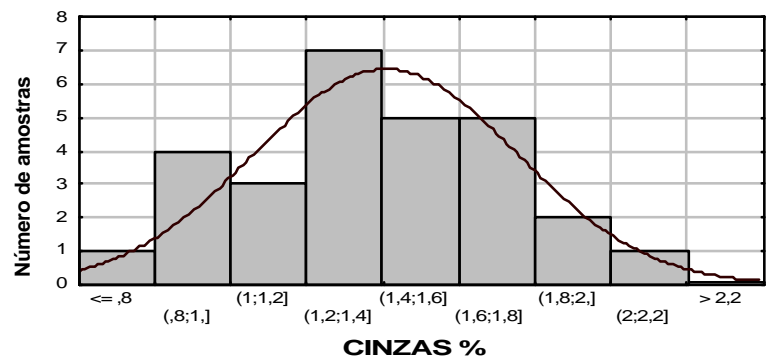

FIGURA 7. Histograma de distribuição de amostras de doce de leite $(n=28)$ em relação aos conteúdos de cinzas.

Teores de cinzas distantes do esperado para o produto, de 1,4\% [11], podem estar relacionados com algum tipo de fraude. Valores muito baixos indicam pequena presença de leite e os elevados, adição excessiva de sais, entre os quais, o bicarbonato de sódio.

\section{6 - Conteúdo de amido das amostras}

O amido é um polissacarídeo de reserva encontrado na maioria dos vegetais. Tem grande aplicação na indústria de alimentos, principalmente como espessante e estabilizante. Em doce de leite permite-se seu emprego, desde que na produção a adição não ultrapasse a $0,5 \mathrm{~g} / 100 \mathrm{~mL}$ de leite. Na Figura 8 os resultados da análise de amido das amostras revela que algumas amostras apresentaram valores muito elevados, o que pode ser considerado uma fraude. Apesar de não haver problema do ponto de vista de segurança alimentar, há redução do valor nutricional, devido a diminui- ção proporcional do conteúdo de proteína, assim como um prejuízo econômico ao consumidor, pois trata-se de um ingrediente de baixo custo em relação ao leite.

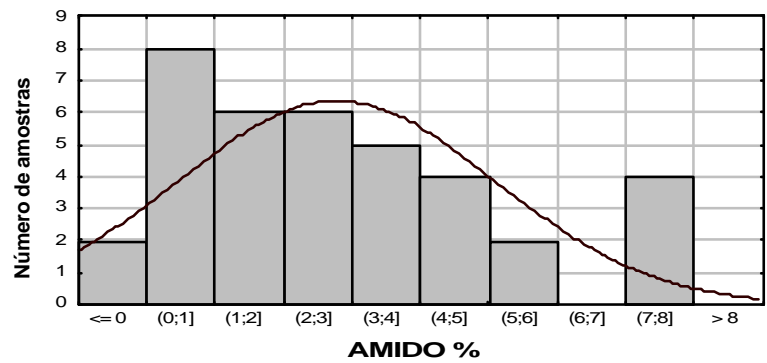

FIGURA 8. Histograma de distribuição de amostras de doce de leite $(n=37)$ em relação aosconteúdos de amido.

As amostras apresentaram desde a ausência até $7,8 \%$ de amido em suas composições. Foram encontradas 15 amostras com teores de amido acima de 3,0\%, das quais seis tinham mais de $5,0 \%$. São valores muito elevados e que baixam os custos de produção, constituindo uma fraude. Considerando-se a adição permitida pela legislação vigente [2], seria impossível atingir esses valores no produto final.

\section{7 - Estatística descritiva}

O Quadro 1 mostra a estatística descritiva dos dados obtidos neste trabalho. Além da composição química foram considerados o preço por quilograma e a capacidade das embalagens na análise. São mostrados os valores médios, mínimos e máximos, assim como o desvio-padrão e o coeficiente de variação para cada uma das variáveis.

QUADRO 1. Estatística descritiva da composição química, do preço por quilograma e da capacidade das embalagens das amostras de doce de leite.

\begin{tabular}{lcccccc}
\hline & número de & & & & Desvio & CV \\
amostras & Média & Mínimo & Máximo & padrão & $\%$ \\
Umidade & 42 & 26,80 & 19,00 & 37,20 & 4,35 & 16,2 \\
Sacarose & 42 & 45,74 & 32,70 & 56,64 & 5,27 & 11,5 \\
Lactose & 42 & 9,32 & 4,66 & 12,68 & 1,93 & 20,7 \\
Glucose & 42 & 2,09 & 0,40 & 3,90 & 0,72 & 34,3 \\
Proténa & 42 & 7,07 & 1,40 & 13,90 & 2,77 & 39,2 \\
Lipídios & 42 & 3,90 & 0,00 & 8,40 & 2,20 & 56,3 \\
Cinzas & 28 & 1,41 & 0,80 & 2,10 & 0,35 & 25,6 \\
Amido & 37 & 2,78 & 0,00 & 7,83 & 2,32 & 83,5 \\
Capac.emb.(g) & 42 & 441,90 & 230,00 & 1000,00 & 148,05 & 33,5 \\
Preço (R $\$ / k g)$ & 41 & 4,32 & 2,16 & 9,97 & 1,98 & 45,8
\end{tabular}

De acordo com o Quadro 1, as amostras apresentaram grandes variações em suas composições químicas, principalmente em relação aos teores de amido $(\mathrm{CV}=83,5 \%)$, lipídios (CV $=56,3 \%)$, proteína (CV = $39,2 \%)$, glucose $(34,3 \%)$, cinzas $(C V=25,6 \%)$ e lactose $(20,7 \%)$. As embalagens das amostras apresentavam capacidades desde 230 até $1000 \mathrm{~g}$ e os preços por quilograma variaram de $R \$ 2,16$ a 9,97. As embalagens eram de polipropileno opaco $(n=15)$ ou transparente $(n=7)$, vidro $(n=8)$ ou lata $(n=12)$.

\section{8 - Correlações entre as variáveis}

O Quadro 2 ilustra as correlações encontradas entre as variáveis estudadas neste trabalho. Consideran- 
do-se a composição do leite, principal ingrediente do produto, observa-se que os teores de proteína e cinzas estão positivamente correlacionados $\left(R^{2}=0,7490\right)$ assim como proteína e lipídios $\left(R^{2}=0,4443\right)$. Lactose está positivamente correlacionada com cinzas $\left(R^{2}=0,4233\right)$, porém não com proteína. É importante destacar que o amido, como se poderia esperar, está negativamente correlacionado com todos os componentes do leite: proteína $\left(R^{2}=-0,6089\right)$, lipídios $\left(R^{2}=-0,5271\right)$, cinzas $\left(R^{2}\right.$ $=-0,7680)$ e lactose $\left(R^{2}=-0,4029\right)$.

QUADRO 2. Matriz de correlação entre as variáveis estudadas

\begin{tabular}{|c|c|c|c|c|c|c|c|c|c|c|}
\hline & ROTEINA & LIPIDIOS & CINZAS & LACTOSE & AMIDO & PESOEMB & $\mathrm{RS} / \mathrm{kg} \mathrm{Gi}$ & Lucos & ICAR & UMII \\
\hline DTEFNA & 1,0000 & $0,4443^{*}$ & $0,7490^{*}$ & 0,0317 & $-0,6089 *$ & $-0,2910$ & 0,1436 & 0,3292 & $-0,3213$ & 0,0293 \\
\hline PIDIOS & $0,4443^{*}$ & 1,0000 & $0,4085^{*}$ & 0,1273 & $-0,5271^{*}$ & $-0,0389$ & $-0,0209$ & 0,1594 & $-0,0303$ & $-0,1152$ \\
\hline NZAS & $0,7490^{*}$ & $0,4085^{*}$ & 1,0000 & 0,4233 & $-0,7680^{*}$ & $-0,3971^{*}$ & 0,2003 & 0,3620 & $-0,3334$ & 0,2212 \\
\hline CTOSE & 0,0317 & 0,1273 & $0,4233^{*}$ & 1,0000 & $-0,4029 *$ & $-0,0823$ & 0,0970 & 0,1415 & $-0,2418$ & 0,2600 \\
\hline MIDO & $-0,6089^{*}$ & $-0,5271^{*}$ & $-0,7680$ * & $-0,4029 *$ & 1,0000 & 0,3589 & $-0,3362$ & $-0,2310$ & $-0,6697$ & 0,1073 \\
\hline ESO_EMB & $-0,2910$ & $-0,0389$ & $-0,3971^{*}$ & $-0,0823$ & 0,3589 & 1,0000 & $-0,5881^{*}$ & $-0,0332$ & $-0,0068$ & 0,0415 \\
\hline S_KG & 0,1436 & $-0,0209$ & 0,2003 & 0,0970 & $-0,3362$ & $-0,5881^{*}$ & 1,0000 & $-0,0706$ & 0,2229 & $-0,2101$ \\
\hline LUCOSE & 0,3292 & 0,1594 & 0,3620 & 0,1415 & $-0,2310$ & $-0,0332$ & $-0,0706$ & 1,0000 & $-0,3704$ & 0,1667 \\
\hline ACAROSE & $-0,3213$ & $-0,0303$ & $-0,3334$ & $-0,2418$ & $-0,0597$ & $-0,0068$ & 0,2229 & $-0,3704$ & 1,0000 & $-0,7494$ \\
\hline ID) & 029 & $-0,1152$ & 0,221 & 0,260 & 0,107 & 0,041 & $.0,2101$ & 0,1667 & $-0,7494^{4}$ & 1,0000 \\
\hline
\end{tabular}

${ }^{*}$ Correlações significativas a $p<0,05000$

$\mathrm{n}=28$ (dados perdidos foram desconsiderados)

Os preços por quilograma das amostras estão negativamente correlacionados com a capacidade das embalagens $\left(R^{2}=-0,5881\right)$. As variáveis umidade e teor de sacarose das amostras se correlacionaram negativamente $\left(R^{2}=-0,7494\right)$, o que era esperado uma vez que, no produto final a sacarose é o componente mais abundante. Os teores de glucose não se correlacionaram com nenhuma variável.

\section{9 - Análise multivariada - Análise de componen- tes principais}

Com o objetivo de compreender melhor a diferenciação das amostras analisadas, fez-se um estudo multivariado dos dados. A análise de componentes principais foi escolhida por permitir uma discussão dos resultados quando explorados considerando-se o peso de todas as medidas obtidas experimentalmente. NaFigura 9 são mostrados os resultados gráficos (scores e loadings) que revelam a separação das amostras e as variáveis mais importantes nessa separação.

O primeiro componente principal (PC1) explica 33,89\% e o segundo (PC2) explica $26,32 \%$ da variância do modelo. A distribuição das amostras é feita de acordo com as variáveis que aparecem na figura da direita. Assim, dividindo-se as figuras em quadrantes conclui-se que as amostras 40, 39, 32 e 34 apresentam elevados teores de amido, enquanto a 1, a 35, a 5 e a 26 têm os maiores teores de sacarose, açúcares totais e matéria seca. As amostras 14 e 8 têm altos conteúdos de proteína, cinzas e lactose. É possível observar que no PC1 o teor de amido está oposto aos teores de lactose, proteína, lipídios e cinzas, como já foi mostrado no Quadro 2.

Os rótulos de algumas amostras apresentaram informações que não corresponderam aos resultados experimentais encontrados. A ausência da indicação da adição de amido nos rótulos de dez amostras é um dos exemplos de problemas com a rotulagem. Em uma amostra a rotulagem nutricional total declarada (carboidratos, proteínas e lipídios) quando somada resultou em um valor muito baixo. Adicionando-se a esse total o máximo de cinzas permitido pela legislação $(2,0 \%)$ não foi possível se atingir o valor de matéria seca de $70 \%$, mínimo exigido pela legislação, revelando um excesso de umidade. A validade de 18 amostras foi declarada como sendo de 12 meses, enquanto em 8 amostras a validade declarada foi de 6 meses e em 5 de 4 meses. Nos rótulos das outras amostras $(n=11)$ havia somente a data de vencimento, não sendo possível determinar o período de validade.

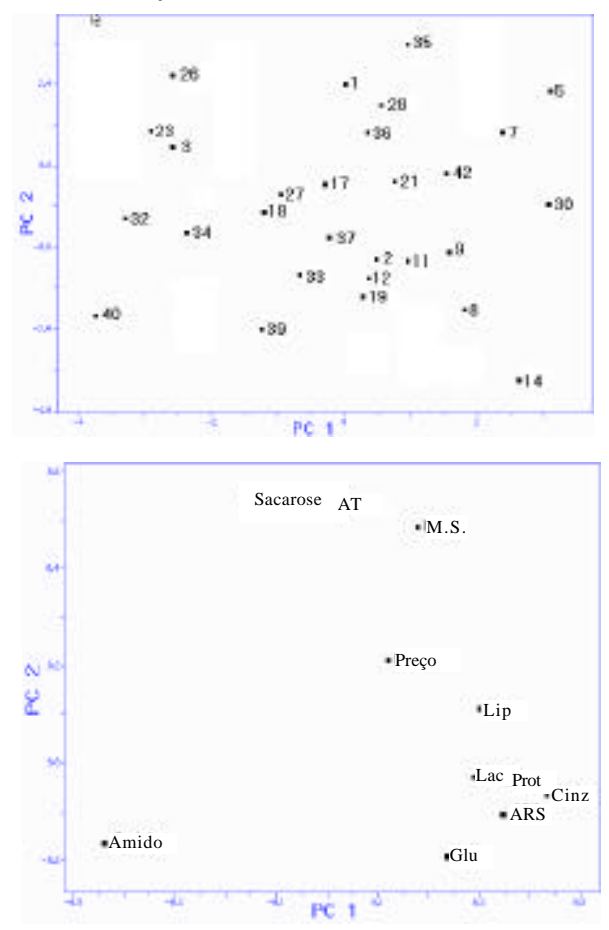

Legenda: AT = açúcares totais; MS = matéria-seca; Preço = preço $/ \mathrm{kg} ;$ Lip = lipídios; Prot = proteína; ARS = açúcares redutores solúveis; Glu $=$ glucose

FIGURA 9. Componentes principais dos dados obtidos. À esquerda scores e à direita loadings.

\section{4 - CONCLUSÕES}

Os resultados permitiram concluir que:

- Algumas amostras apresentaram excesso de umidade $(n=10)$, valores de proteína muito baixos $(n=8)$ e de amido muito elevados $(n=15)$, estando em desacordo com a legislação vigente;

- O conteúdo de amido correlacionou-se negativamente com todos os componentes do leite, ou seja, lactose, proteína, lipídios e cinzas, indicando a substituição de parte do leite por amido para reduzir custos;

- Proteína e cinzas, componentes com teores relativamente constantes no leite, apresentaram elevado coeficiente de correlação positivo, estando relacionados com a presença de leite nas amostras; 
- A análise de componentes principais permitiu concluir que as amostras foram diferenciadas pela presença de amido e pelos conteúdos de matéria-seca (sacarose ou açúcares totais);

- A constatação de que há amostras em desconformidade com a legislação revela a necessidade de fiscalização da qualidade por órgãos competentes a fim de impedir que continuem havendo fraudes que trazem prejuízos ao consumidor.

\section{5 - REFERÊNCIAS BIBLIOGRÁFICAS}

[1] BRASHOLANDA S.A. Doce de leite. Processo contínuo. Alimentos \& Tecnologia, São Paulo, Ano III, n.38, p. 6364, 1991.

[2] BRASIL. Ministério da Agricultura e do Abastecimento, Secretaria de Defesa Agropecuária, Departamento de Inspeção de Produtos de Origem Animal. Portaria N. ${ }^{0} 354$, de 4 de setembro de 1997. Disponível em: http:// www.agricultura.gov.br/das/dipoa/port354.html Acesso em: 16 nov. 2000.

[3] DAHLQUIST, A. Determination of maltase and isomaltase activities with a glucose oxidase reagent. Biochem.J., London, n.80, p.547-51, 1961.

[4] DEMIATE, I.M.; BARANA, A.C.; CEREDA, M.P.; WOSIACKI, G. Organic acid profile of commercial cassava sour starch. Ciênc. Tecnol. Aliment., Campinas, v. 19, n.1, p.131-5, 1999.

[5] DEMIATE,I.M.; SENGER,S.A.; VOGLER,Z.; CEREDA,M.P.; WOSIACKI,G. Características de qualidade de amostras de polvilho azedo produzido ou comercializado no Estado do Paraná. Arquivos de Biologia e Tecnologia, Curitiba, v.40, n.2, p.331-49, 1997a.

[6] DEMIATE,I.M.; SOUZA,T.O.de; PUGSLEY,S.; CEREDA,M.P.; WOSIACKI,G. Características de qualidade de amostras de polvilho azedo. Parte 2. Santa Catarina. Agropecuária Catarinense, Florianópolis, v.10, n.4, p.51-6, 1997b.

[7] FERREIRA, V.L.P.; HOUGH, G.; YOTSUYANAGI, K. Cor de doce de leite pastoso. Coletânea do ITAL, Campinas, v. 19, n. 2, p. 134-143, 1989.

[8] HODGE, J.E.; HOFREITER, B.T. Determination of reducing sugars and carbohydrates. In: WHISTLER, R.L.; WOLFORM, M.L. (eds.) Methods in Carbohydrate Chemistry, v. I (Analysis and Preparation of Sugars), New York : Academic Press, p. 380-393, 1962.

[9] HOUGH, G.; BUERA, M.P.; MARTINEZ, E.; RESNIK, S. Effect of composition on non-enzymatic browning rate in dulce de leche-like systems. Anales de la Associación Química Argentina, Buenos Aires, v. 79, n.1, p.31-40, 1991.

[10] IAL - Normas Analíticas do Instituto Adolfo Lutz. 3ae ed., São Paulo : Instituto Adolfo Lutz, 1985. 533p. (Volume 1, Métodos Químicos e Físicos para Análise de Alimentos).
[11] MARTINS, J.F.P.; LOPES, C.N. Doce de leite: aspectos da tecnologia de fabricação. Campinas : ITAL, 1980. 37p. (Instruções Técnicas, no 18).

[12] NAVARRO, A.S.; FERRERO, C.; ZARITZKY, N.E. Rheological characterization of Dulce de Leche by dynamic and steady smear measurements. Journal of Texture Studies, Westport, v.30, n.1, p.43-58, 1999.

[13] NELSON, H. A photometric adaptation of the Somogyi method for determination of glucose. Journal of Biological Chemistry, Bethesda, v.153, p.375-80, 1944.

[14] PAULETTI, M.; CALVO, C.; IZQUIERDO, L.; COSTELL, E. Color and texture of Dulce de leche, a confectionary dairy product - Selection of instrumental methods for industrial quality control. Revista Española de Ciência y Tecnologia de Alimentos, Valencia, v.32, n.3, p.291-305, 1992.

[15] PAVLOVIC, S.; SANTOS, R.C.; GLORIA, M.B.A. Maillard reaction during the processing of Doce de leite. Journal of the Science of Food and Agriculture, London, v.66, n.2, p.129-132, 1994.

[16] PAVLOVIC, S.; SANTOS, R.C.; SILVA, M.E.; GLORIA, M.B.A. Effect of processing on the nutritive value of Doce de leite, a typical Latin-American confectionary product. Arquivos de Biologia e Tecnologia, Curitiba, v.35, n.4, p.691-698, 1992.

[17] PINTO, R.V. Doce de leite - Fabricação tradicional. Revista do ILCT, Juiz de Fora, v. 34, n. 205, p. 37-8, 1979.

[18] ROVEDO, C.O.; VIOLLAZ, P.E.; SUAREZ, C. The effect of $\mathrm{pH}$ and temperature on the rheological behavior of Dulce de leche, a typical dairy Argentine product. Journal of Dairy Science, Champaign, v.74, n.5, p.1497-1502, 1991.

[19] SANTOS, D.M.; MARTINS, J.P.F.; SANTOS, N.C.V. Arenosidade e outros problemas do doce de leite. Boletim do ITAL, Campinas, v.52, p.61-80, 1977.

[20] SILVEIRA, N.V.V. Grupo de trabalho: legislação de alimentos. Boletim da SBCTA, Campinas, v.29, n.1, p.77-78, 1995.

[21] SOUZA, G. de; OLIVEIRA, A.J. de; SHIROSE, I.; VALLE, J.L.E.; CARVALHO, C.R.L. Utilização de abóbora e moranga na produção de doce de leite pastoso com coco. Anais da ESALQ, Piracicaba, v.47, parte 2, p.609-623, 1990.

[22] SOMOGYI, M. Notes on sugar determination. Journal of Biological Chemistry, Bethesda, v.195, n.1, p.19-23, 1952.

[23] VITOLO, M., CUNHA, B.C.A. Extração de invertase a partir de levedura de panificação: efeito da pressão osmótica e da natureza da solução salina. Rev. Farm. Bioquím. Univ. S. Paulo, São Paulo, v.17, n.1, p.86-92, 1981.

\section{6 - AGRADECIMENTOS}

Os autores agradecem ao CNPq e à Universidade Estadual de Ponta Grossa (Programa PIBIC - CNPq/ UEPG) pela concessão de bolsa de iniciação científica que está sendo de fundamental importância para o desenvolvimento da pesquisa e à NOVO Nordisk pelo fornecimento das enzimas. 